\title{
Students' Reflective Abstraction in Solving Number Sequence Problems
}

\author{
Mohammad Djasulia, Cholis Sa'dijah ${ }^{\mathrm{b}}$, I Nengah Partac, Tjang Daniel \\ Chandrad $^{\mathrm{d}}$ \\ aSekolah Menengah Atas (SMA) Negeri 4 Pasuruan, INDONESIA \\ $b, c, d$ Universitas Negeri Malang, INDONESIA
}

\begin{abstract}
This study is qualitative in nature, aims to describe students' reflective abstraction in solving problems related to number sequence. As subjects of this study are 6 students, composed of 3 students ( 2 female and one male) from State Senior High School (SMAN) 1 Pasuruan, and 3 students ( 2 male and 1 female) from SMAN 1 Pandaan, East Java, Indonesia. In this study, the researchers were acted as human instruments. Narrative description was compiled by assembling descriptions of reflective abstraction stages associated with the criteria of high, intermediate, or low thinking processes, and the cognitive levels including knowledge application and reasoning. The results suggest that students' strategies of problem solving are not directly proportional to their level of reflective abstraction. It was also found that students' reflective abstraction furnish students' individually unique solution, simply complicated, while interventions are important in its attainments.
\end{abstract}

KEYWORDS

Stages and levels of reflective abstraction, high school students, number sequence
ARTICLE HISTORY

Received 15 May 2017

Revised 10 July 2017 Accepted 22 August 2017

\section{Introduction}

The ability to perform abstraction is an important skill in mathematics meaning making (Hazzan \& Zazkis, 2005). In other words, mathematics abstraction skills construct a meaning for any entity. Accordingly, Panasuk (2011) states the significance of students' level of abstractions in learning mathematics. Hence, developing students' abstraction competence is vital in mathematics education. Mitchelmore \& White (2004), quoting Herskowitz et.al., define abstraction as a vertical reorganizing activity of pre-constructed

CORRESPONDENCE Mohammad Djasuli $\square$ mohammad.djasuli65@gmail.com

(c) 2017 M. Djasuli et al.

Open Access terms of the Creative Commons Attribution 4.0 International License apply. The license permits unrestricted use, distribution, and reproduction in any medium, on the condition that users give exact credit to the original author(s) and the source, provide a link to the Creative Commons license, and indicate if they made any changes. (http://creativecommons.org/licenses/by/4.0/) 
mathematical concepts through a new mathematical structure. Throughout the relationship construction of generalizations, of proofs, or of new problem solving strategies, new mathematics objects are formed.

Goedecke (2013) concludes that abstraction refers to generalization and modeling. Goedecke also states that abstraction beneficial to simplify or to make easier a work or people's mind, to clarify connections, to open new areas, to solve problem, and to create new ideas. Wiryanto (2014) asserts that abstraction is a mental processed activity in constructing a mathematical concept consisting of inter-structure relationship or mathematical objects. For instance, abstraction in the form of language, as follows: Mosquitoes, flies, and dragonflies are abstracted as insects; Cows, horses, and buffalos are abstracted as ruminates; Rats, foxes, and rabbits are abstracted as rodents. Then, insect, ruminate, and rodent are abstracted as animal. It is obligatory for teacher to teach the conceptualization of abstraction levels to enhance students' abstraction skills (Hazzan, 1991; Hazzan \& Zazkis, 2005), so mathematical abstractions, especially in school mathematics learning need to be acknowledged, comprehended, and applied by both teachers and school policy makers.

Von Glasersfeld (1991), and Gray \& Tall (2007), states that Piaget (1972) divides abstraction into three types, namely empirical abstraction, pseudoempirical abstraction, and reflective abstraction. Explaining further, Wiryanto (2014) mentions that empirical abstraction focuses on the way children build their knowledge, definition and characteristics of real objects. Pseudo-empirical abstraction highlights the way children construct knowledge, definition and characteristics of action or behavior of real objects. Reflective abstraction focuses on the idea of action or behavior, while operation becomes a thematic object on thoughts or assimilation related to mental operation categorization and abstraction towards mental objects. In short, empirical abstraction refers to the conceptualization of real object in the form of a new concept of knowledge, pseudo-empirical abstraction is the conceptualization of action towards real objects thus create new concept, while reflective abstraction is best defined as the conceptualization of brain-owned, mental, rather than real objects. As an illustration, given three apples and three oranges arranged, lined up in the same fruit lane. Both three apples and three oranges in a lane are abstracted as an empiric abstraction of a set. An action of connecting paralleled apple and orange sets individually is the pseudo-empirical abstraction. A new concept of knowledge emerges in the form of $1-1$, is called reflective abstraction.

Mitchelmore \& White (2007) differentiate and divide abstraction into two categories: empirical abstraction, and theoretical abstraction. In an empirical abstraction, the process of knowledge construction of an abstract object is factual based. Empirical abstraction focuses on identifying common and important features resulting in new concepts. The concept also called as a general abstract. On the contrary, theoretical abstraction means the process of concept construction based on several theories.

There are only a few research related to reflective abstraction, for example, Sopamena's (2016) and Wiryanto's (2014) research on the characteristics of reflective abstraction, Sudirman's (2012) research on students' cognitive process in constructing function composition involving reflective abstraction, Nurhasanah's (2010) study on the students' process of abstraction 
in solving mathematical geometric problem. Previous researcher Capetta (2007) had conducted a study on reflective abstraction concept based on limit concept, Paschos \& Farmaki (2006) directed research related to reflective abstraction on relationship of distance and travel time concepts, Cifarelli (1988) administered research related to students' reflective abstraction levels description achieved when solving algebraic problem, of which consisting of recognition, representation, structural abstraction, and structural awareness, while Goodson-Espy (1988) organized a research on undergraduate students' transition when using arithmetic on algebra.

Referring to reflective abstraction in individual cognitive process, Piaget (in Dubinsky, 2002) mentions its component as follows: Interiorization, Coordination, Encapsulation, and Generalization. Reversal component, as maintained by Piaget, is embedded in the four components, but Dubinsky separately states that reversal is the fifth component, therefore Dubinsky developed Piaget's reflective abstraction theory with his research on students' integral concepts.

Based on the literature review of researches on reflective abstraction, then the study on solution writing stage and students' reflective abstraction levels is relevant to be conducted. In particular, for high school students as subjects, as it seems preferable nowadays to conduct a research to undergraduate students due to their mental readiness and cognitive maturity.

\section{Methods}

This study is qualitative in nature. As the participants of this study were 6 students, composed of 3 students ( 2 female and one male) from State Senior High School (SMAN) 1 Pasuruan, and 3 students (2 male and 1 female) from SMAN 1 Pandaan. As in qualitative descriptive research, the researcher was acted as human instrument. The research results were narrative descriptions of subjects' reflective abstraction of solution stage, related to their level of abstractions. The solution writing steps were shown in the form of diagrams along with its level.

The research problem of this study is: how students find the formal formulation of $n$-th term of the following irregular sequence number:

a. Determine the three next numbers from the sequence number $1,2,4, \ldots$, $\ldots, \ldots$.

b. If the sequence number is continued to- $n$, please write the general formulation of the $n$-th term.

That problem appears as a simple problem, but it has an extensive challenge to be solved. The instruments used in this study were designed to develop solution from students' reflective abstraction in the sequence number with irregular or unknown pattern which was not familiar for the subjects. Therefore, subjects were demanded to write the formulation of $n$-th term via reflective abstraction.

Narrative description was compiled by assembling descriptions of reflective abstraction stages associated with the criteria of high, intermediate, or low thinking processes, and the cognitive levels including knowledge application, and reasoning. Furthermore, the narrative description was shown in the form of a diagram. 


\section{Results and Discussion}

The results show that all of the subjects: S1, S2, S3, S4, S5, and S6 had demonstrated their works manifest as solutions indicating their reflective abstractions. Several subjects given the same sequence number constructed the similar general formulation of $n$-th term. In other words, students' reflective abstraction in solving sequence number problem is individualistic, and answered in a unique way; therefore, reflective abstraction produces unique and individualistic solutions. In the following table, we can see the solution stages indicators in reflective abstraction level.

Table 1. Solution Stages Indicator in Reflective Abstraction Level

\begin{tabular}{|c|c|c|}
\hline $\begin{array}{c}\text { Reflective } \\
\text { Abstraction } \\
\text { Level }\end{array}$ & Solution Stages & Subjects' Solution Indicators \\
\hline \multirow{3}{*}{ Recognition } & $\begin{array}{l}\text { In-depth observing number } \\
\text { pattern }\end{array}$ & $\begin{array}{l}\text { Consciously writing three next numbers or } \\
\text { more }\end{array}$ \\
\hline & \multirow{2}{*}{$\begin{array}{l}\text { Planning action towards } \\
\text { obtained number pattern }\end{array}$} & Writing initial or code of the numbers \\
\hline & & Making pattern of new sequence number \\
\hline \multirow{4}{*}{ Representation } & \multirow{2}{*}{$\begin{array}{l}\text { Designing strategy through } \\
\text { new pattern }\end{array}$} & Writing pattern in symbols \\
\hline & & Convert an old pattern into a new one \\
\hline & \multirow[t]{2}{*}{$\begin{array}{l}\text { Conducting an action based on } \\
\text { the strategy }\end{array}$} & $\begin{array}{l}\text { Writing a symbol of several symbols or } \\
\text { patterns }\end{array}$ \\
\hline & & $\begin{array}{l}\text { Defining a pattern of several symbols or } \\
\text { patterns }\end{array}$ \\
\hline \multirow{3}{*}{$\begin{array}{l}\text { Structural } \\
\text { Abstraction }\end{array}$} & \multirow{3}{*}{$\begin{array}{l}\text { Modelling action into a new } \\
\text { concept }\end{array}$} & Writing pattern into a concept \\
\hline & & Defining concepts into new variables \\
\hline & & Writing conditions of concept definition \\
\hline \multirow{3}{*}{$\begin{array}{l}\text { Structural } \\
\text { Awareness }\end{array}$} & \multirow[t]{2}{*}{$\begin{array}{l}\text { Concluding a new concept as a } \\
\text { formal form }\end{array}$} & $\begin{array}{l}\text { Concluding decisions of a phenomenon } \\
\text { verbally }\end{array}$ \\
\hline & & $\begin{array}{l}\text { Stating mathematical form of the } n \text {th term } \\
\text { formally }\end{array}$ \\
\hline & $\begin{array}{l}\text { Investigating the validity of } \\
\text { the formal form }\end{array}$ & $\begin{array}{l}\text { Testing generality of the formal form for any } \\
n\end{array}$ \\
\hline
\end{tabular}

Table 1 above had become a reference to analyze the data collected in this study, and then those data were presented in the form of description, table, and diagram related to the subjects' reflective abstraction solution and reflective abstraction level.

In this article, we give an example of Subject S5's solutions. Figure 1a, Figure $1 \mathrm{~b}$ and Figure 2 demonstrate the differences in reflective abstraction of S5 solutions. 


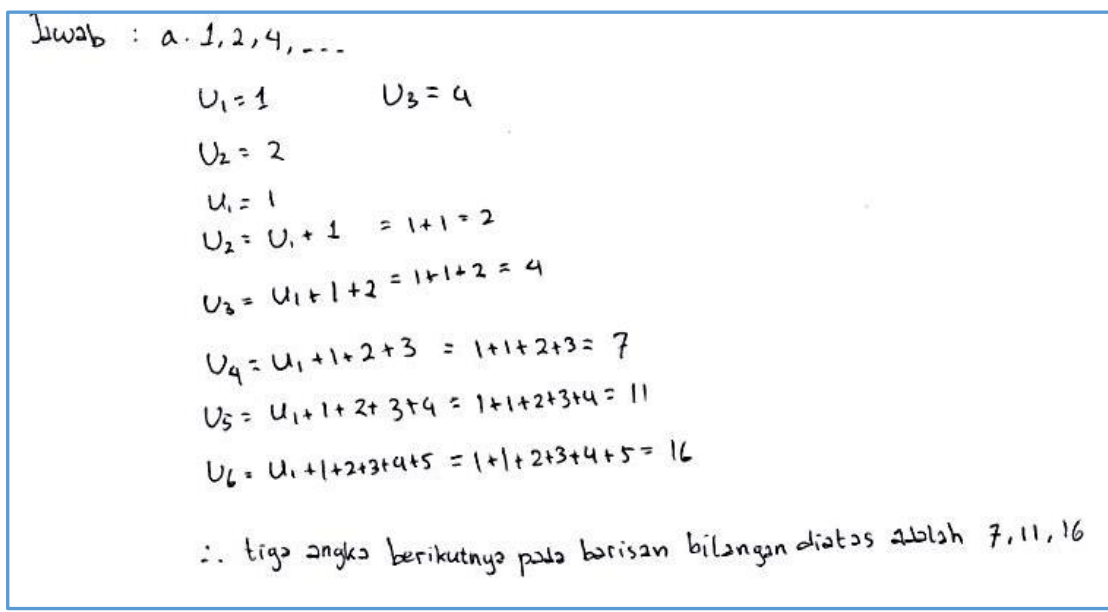

Figure 1a. Subject S5's solution without reflective abstraction

Figure 1a indicates that S5 applied only individual's knowledge on the term calculation patterns. Although his answer shows signs of new pattern construction by adding previous term, but the reflective abstraction did not appear.

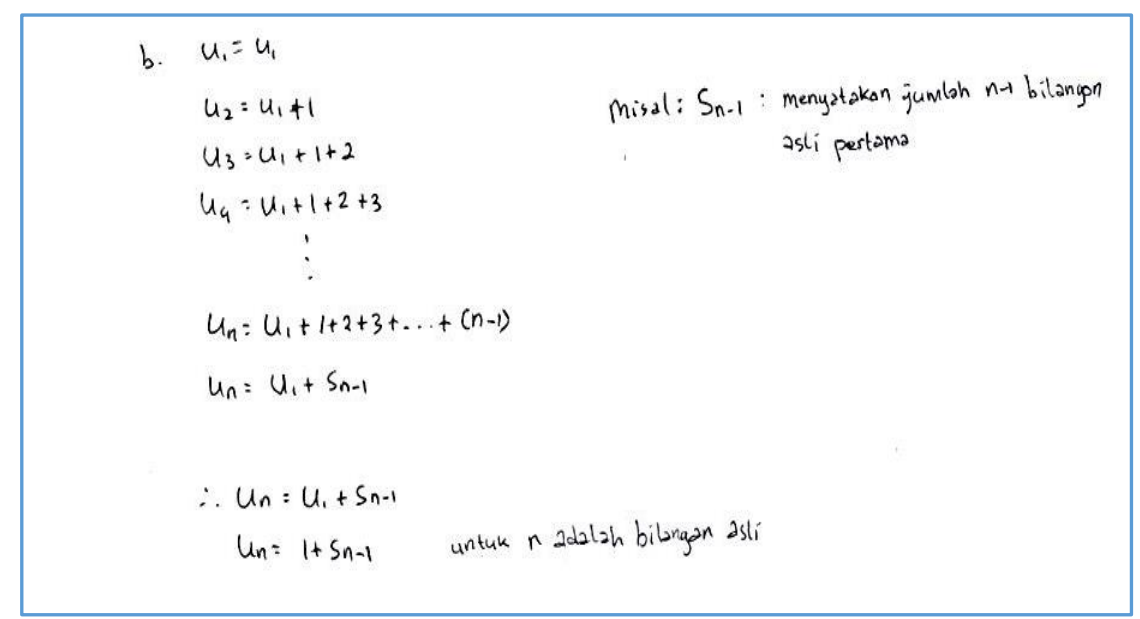

Figure 1b. Subject S5's solution without reflective abstraction

Actually, Figure 1b was an extension of Figure 1a of subject S5's solution. In Figure $1 \mathrm{~b}$, subject S5 explicitly conceptualized $U_{n}=1+S_{n-1}$ by means of concept interpretation process, but not reasoning process. In the following Figure 2, we show the subject S5's construction of the reflective abstraction in his solution writing. 


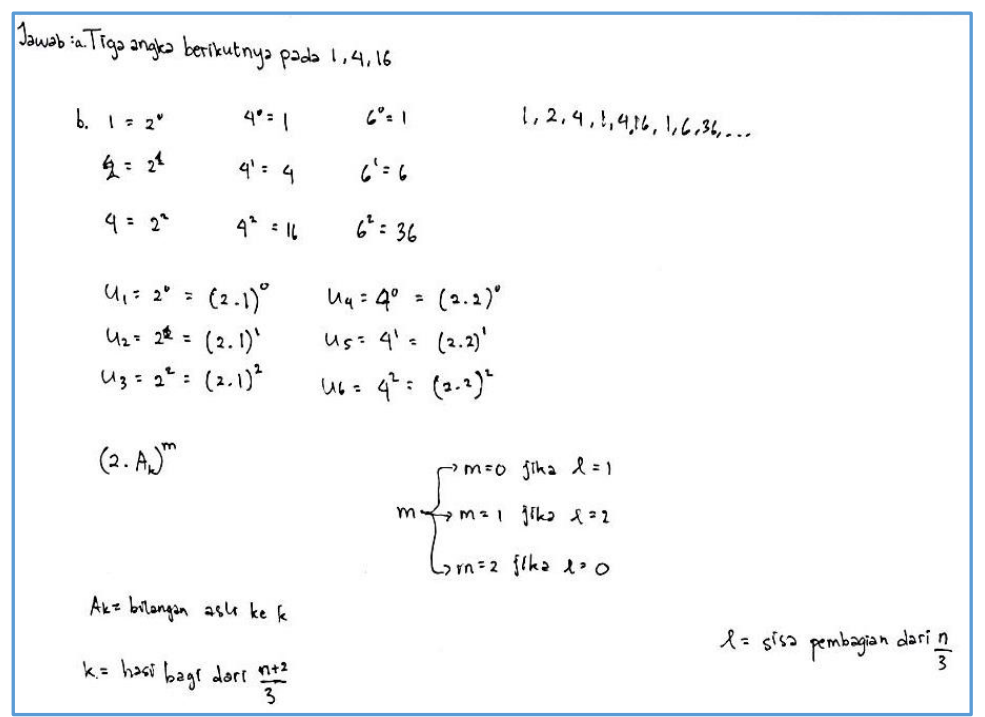

Figure 2. Subject S5's Solution with Reflective Abstraction

In Figure 2 we see that S5 performed reflective abstraction in complicated and intricate forms. The indicator of the word intricate is the strategy of formula finding of the $n$-th term was difficult, while the word complicated is derived from the formal form which is hard to remember. It is based on S5's thinking aloud transcript. The sequence numbers in Figure 1 and Figure 2 are different due to researchers' intervention in stimulating S5 to perform reflective abstraction.

Several fragments of S5's thinking aloud and dialogues between one of the researcher $(\mathrm{P})$ and Subject $(\mathrm{S})$ could be beneficial in understanding S5's reflective abstraction, as in the following dialogue:

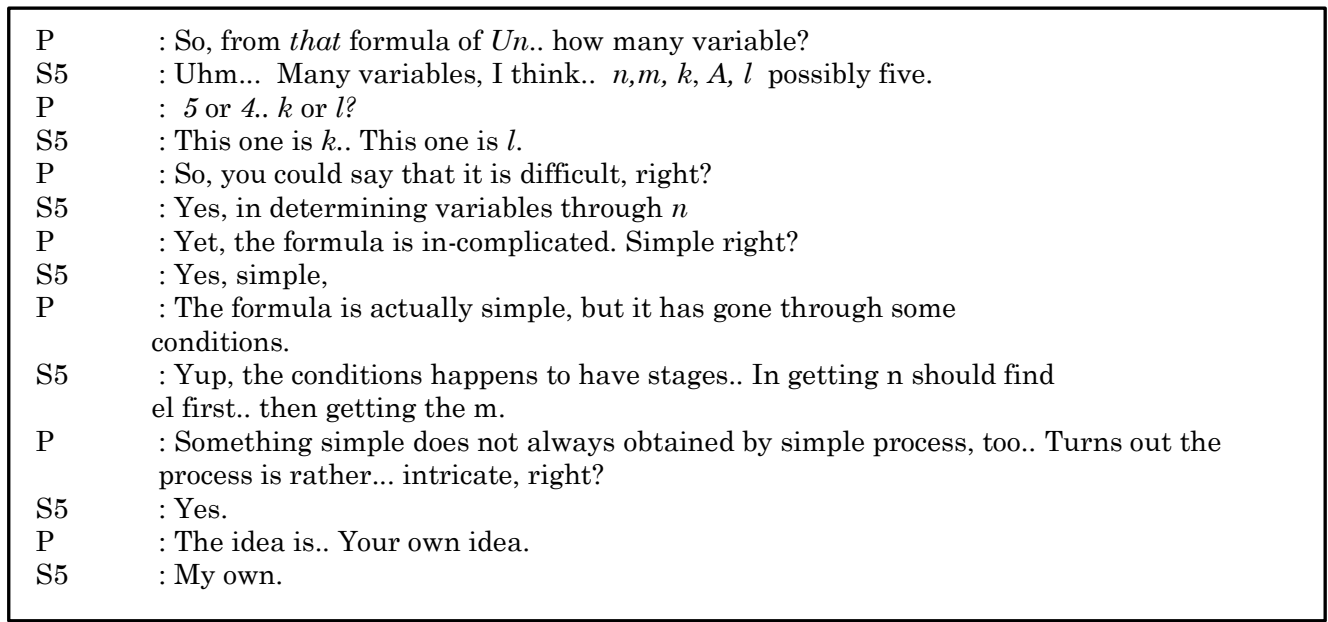

Figure 3. Fragment of dialogue between subject S5 and the researcher 
Based on Figure 1, 2 and 3, the subject S5's solution stages can be described as follows:

1. Starting the problem solving by writing the next following number in a sentence on 1, 4, 16. Although it is inaccurate in writing the word on, but S5 clarified the sentence by writing the intended sequence number: $1,2,4,1,4$, $16,1,6,36, \ldots$. This exhibits that S5 has been able to understand the problem, to remember activities in constructing sequence number, and is able to identify previous activities in the supporting data.

2. Creating a pattern by arranging sequence numbers on the pre-existed sequence number in the order of three numbers from top to bottom continued with the next three numbers to the right side of the previous order.

3. Creating the same exponential number pattern and cardinal numbers, which was 2 , so it is written that for number $1=2^{0}, 2=2^{1}, 4=2^{2}$

4. Creating the same exponential number pattern and cardinal numbers, which was 4 , so it is written that for number $1=4^{0}, 4=4^{1}, 16=4^{2}$

5. Creating the same exponential number pattern and cardinal numbers, which was 6 , so it is written that for number $1=6^{0}, 6=6^{1}, 36=6^{2}$

6. Continuing the result of the same exponential number patterns and cardinal numbers of 2,4 , and 6 as the $n$-th term. For $U_{1}=2^{0}, U_{2}=2^{1}, U_{3}=2^{2}$, $U_{4}=4^{0}, U_{5}=4^{1}, U_{6}=4^{2}, U_{7}=6^{0}, U_{8}=6^{1}$, and $U_{9}=6^{2}$

7. Rearranging all results of exponential number patterns and cardinal numbers 2, 4, dan 6 in the concept of multiplication number of 2 . Then, S5 wrote it down as $U_{1}=2^{0}=(2.1)^{0}, U_{5}=4^{1}=(2.2)^{1}$, and $U_{9}=6^{2}=$ $(2.3)^{2}$ and so on.

8. Concluding new structure with $\left(2 . A_{k}\right)^{m}$ as the strategy for the next stage.

9. Defining variable $m$ as $m= \begin{cases}m=0 & \text { jika } l=1 \\ m=1 & \text { jika } l=2 \\ m=2 & \text { jika } l=0\end{cases}$

10. Defining $A_{k}$ as natural number to- $k$

11. Stating relationship between $k$ in $n$, which $k$ was the quotient of $\frac{n+2}{3}$

12. Stating relationship between $l$ om $n$, which $l$ was the residual division of $\frac{n}{3}$

13. Drawing a conclusion by stating that $U_{n}=\left(2 . A_{k}\right)^{m}$ was the general formula of the $n$-th term.

The first stage is regarded as the level of recognition, because S5 showed the capability to identify the previous activities related to sequence number pattern by creating the desired sequence number. The second stage is categorized as the level of representation, because S5 was able to create a pattern and perform alternative solution method. The third, fourth, fifth, sixth, and seventh stages were parts of levels of structural abstraction, as S5 expressed capability to develop a new problem solving strategy and also arrange a new problem structure.

Besides, the eighth stage is referred to the level of structural awareness, because in this stage S5 reflected the obtained decision, of which $\left(2 . A_{k}\right)^{m}$ that would be followed up in the next stage. The ninth stage is the structural abstraction, and the tenth stage is the level of representation. The eleventh and twelfth stages are also the structural abstraction as S5 anticipated the potential 
difficulty source if no relationship determinant between the related variables. Finally, the thirteenth stage is the level of structural awareness, because S5 is consciously writing back the resume as the conclusion of the problem.

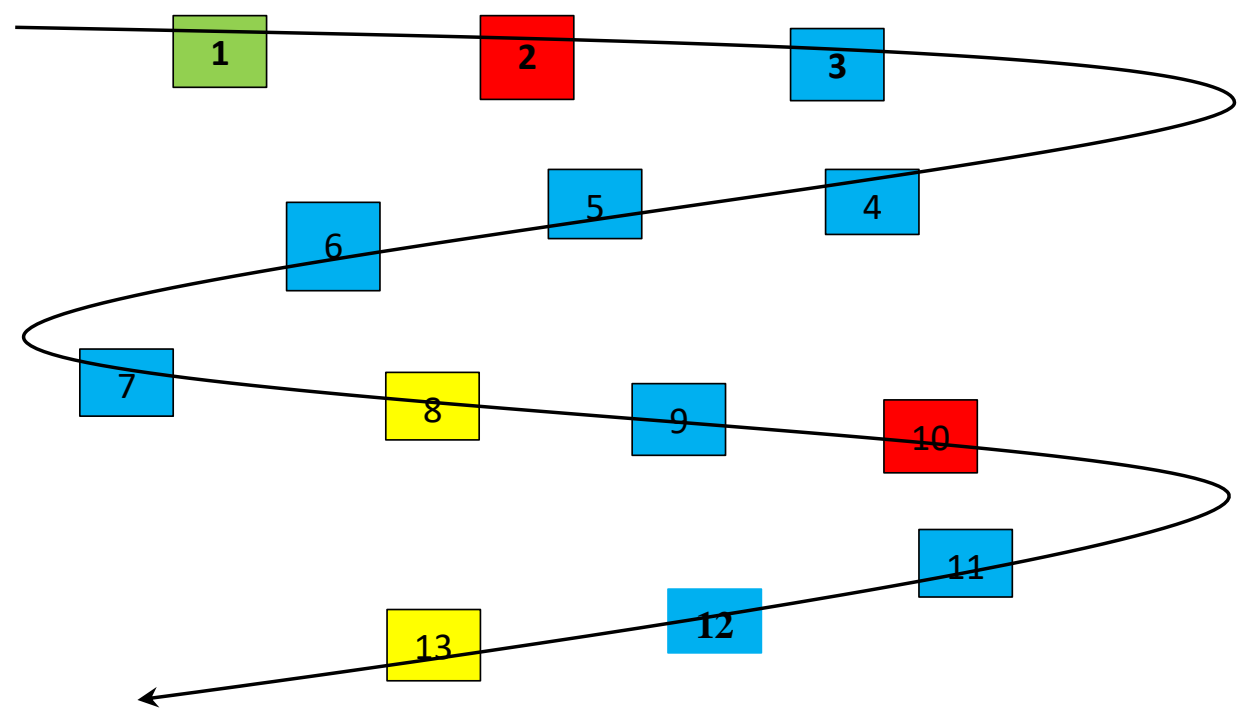

Figure 4. Stages and Levels of Subject S5's Reflective Abstraction

Diagram details:

: Solution stage on the introductory level

: Solution stage on the representation level

: Solution stage on the structural abstraction level

: Solution stage on the awareness abstraction level

Viewed from cognitive levels, subject S5 could be determined as subject with reasoning competence, because S5 demonstrates a way of establishing a general formula of $n$-th term of the sequence number through logical conclusion drawing. Moreover, the thinking of S5 can be categorized as Higher Order Thinking Skills (HOTS), referring to his ability to conduct a high leveled reasoning. Subject S5 fulfilled the indicator of being able to make individual idea creatively by constructing new knowledge based on the pre-existed knowledge.

In addition, in the following table, we summarized the reflective abstraction description of Subject S5.

Table 2. The Description of the Subject S5's Reflective Abstraction

\begin{tabular}{|c|c|}
\hline $\begin{array}{c}\text { Reflective } \\
\text { Abstraction Level }\end{array}$ & Description \\
\hline Recognition & The subject started by writing sequence number of $1,2,4,1,4,16,1,6,36, \ldots$ \\
\hline
\end{tabular}




\begin{tabular}{|c|c|}
\hline & $\begin{array}{l}\text { which shown subject's comprehension of the problem. Reviewing the written } \\
\text { sequence number, it appeared that subject made a unique plan, as he stated } \\
\text { that this sequence number was difficult to arrange in order to find a general } \\
\text { form of the } n \text {th term. }\end{array}$ \\
\hline Rep & $\begin{array}{l}\text { The subject started by arranging pattern of numbers by categorizing the } \\
\text { number into groups of three. Level of representation was performed once more } \\
\text { in the tenth stage when he defined } A_{k} \text { as ordinal number to- } k \text {. Subject had } \\
\text { prepared a strategy to be used on the higher level. }\end{array}$ \\
\hline & $\begin{array}{l}\text { The third to the seventh stages showed that subject had reached structural } \\
\text { abstraction level by creating the same exponential number pattern and ordinal } \\
\text { numbers for every pattern. From the exponential number patterns, the subject } \\
\text { completely arranged it into a new structure in the form of multiplication of } 2 \text {. } \\
\text { The ninth, eleventh, and twelfth steps respectively exhibited that the subject } \\
\text { had been able to define variable } m \text { in } n \text {, as well as to state relationship between } \\
k \text { and } l \text { in } n \text {. }\end{array}$ \\
\hline $\begin{array}{l}\text { Structural } \\
\text { Awareness }\end{array}$ & $\begin{array}{l}\text { On stage eighth, the subject performed structural awareness by concluding a } \\
\text { new structure with the formula of }\left(2 . A_{k}\right)^{m} \text {. The subject's ability in abstraction } \\
\text { awareness reappeared on the thirteenth stage when he concluded }\left(2 . A_{k}\right)^{m} \text { as } \\
U_{n} \text {. }\end{array}$ \\
\hline \multicolumn{2}{|c|}{$\begin{array}{l}\text { Subject S5 has high-leveled thinking capability, and high reasoning level of cognitive. The two } \\
\text { conditions are the main assets of subject's reflective abstraction in solving problems, especially on } \\
\text { sequence numbers. Besides, subject S5 showed only } 15 \text { stages to demonstrate the capability to find } \\
\text { new knowledge. He was tactical in formulating a difficult problem into a simpler problem. In } \\
\text { addition, subject S5 is able to overcome difficulties related to stages of reflective abstraction levels } \\
\text { without further intervention. }\end{array}$} \\
\hline
\end{tabular}

In the following table, we present the solution process of subject S5 in terms of the reflective abstraction.

Table 3. Subject S5's Solution Process in the Solution Stage

\begin{tabular}{|c|c|c|}
\hline Solution Stage & No & Subject's Reflective Abstraction Solution Process \\
\hline \multirow[t]{2}{*}{$\begin{array}{l}\text { In-depth observing } \\
\text { the pattern of } \\
\text { sequence number }\end{array}$} & 1 & $\begin{array}{l}\text { Starting the problem solving by writing the next following number in } \\
\text { a sentence on } 1,4,16 \text {. Although it is inaccurate writing the word on, } \\
\text { but subject S5 clarified the sentence by writing the intended } \\
\text { sequence number: } 1,2,4,1,4,16,1,6,36, \ldots \text { This exhibits that S5 } \\
\text { has been able to understand the problem, to remember activity in } \\
\text { constructing sequence number, and is able to identify previous } \\
\text { activity in the supporting data. }\end{array}$ \\
\hline & 2 & $\begin{array}{l}\text { Creating a pattern by arranging sequence numbers on the pre- } \\
\text { existed sequence number in the order of three numbers from top to } \\
\text { bottom, continued with the next three numbers to the right side of } \\
\text { the previous order. }\end{array}$ \\
\hline \multirow{3}{*}{$\begin{array}{l}\text { Planning an action } \\
\text { based on the } \\
\text { strategy }\end{array}$} & 3 & $\begin{array}{l}\text { Creating the same exponential number pattern and cardinal } \\
\text { numbers, which was } 2 \text {, so it is written that for number } 1=2^{0}, 2= \\
2^{1}, 4=2^{2}\end{array}$ \\
\hline & 4 & $\begin{array}{l}\text { Creating the same exponential number pattern and cardinal } \\
\text { numbers, which was } 4 \text {, so it is written that for number } 1=4^{0}, 4= \\
4^{1}, 16=4^{2}\end{array}$ \\
\hline & 5 & $\begin{array}{l}\text { Creating the same exponential number pattern and cardinal } \\
\text { numbers, which was } 6 \text {, so it is written that for number } 1=6^{0}, 6= \\
6^{1}, 36=6^{2}\end{array}$ \\
\hline $\begin{array}{l}\text { Designing strategy } \\
\text { through new } \\
\text { pattern }\end{array}$ & 6 & $\begin{array}{l}\text { Continuing the result of the same exponential number patterns and } \\
\text { cardinal numbers of } 2,4 \text {, and } 6 \text { as tribe to- } n \text {. For } U_{1}=2^{0}, U_{2}=2^{1} \text {, } \\
U_{3}=2^{2}, U_{4}=4^{0}, U_{5}=4^{1}, U_{6}=4^{2}, U_{7}=6^{0}, U_{8}=6^{1} \text {, and } U_{9}=6^{2}\end{array}$ \\
\hline $\begin{array}{l}\text { Conducting strategy } \\
\text { in the form of an }\end{array}$ & 6 & $\begin{array}{l}\text { Continuing the result of the same exponential number patterns and } \\
\text { cardinal numbers of } 2,4 \text {, and } 6 \text { as the } n \text {th term. } U_{1}=2^{0}, U_{2}=2^{1} \text {, }\end{array}$ \\
\hline
\end{tabular}




\begin{tabular}{|c|c|c|}
\hline \multirow[t]{2}{*}{ action } & & $U_{3}=2^{2}, U_{4}=4^{0}, U_{5}=4^{1}, U_{6}=4^{2}, U_{7}=6^{0}, U_{8}=6^{1}$, and $U_{9}=6^{2}$ \\
\hline & 7 & $\begin{array}{l}\text { Rearranging all results of exponential number patterns and cardinal } \\
\text { numbers } 2,4 \text {, and } 6 \text { in the concept of multiplication number of } 2 \text {. } \\
\text { Then, S5 wrote it down as } U_{1}=2^{0}=(2.1)^{0}, U_{5}=4^{1}=(2.2)^{1} \text {, and } \\
U_{9}=6^{2}=(2.3)^{2} \text { and so on. }\end{array}$ \\
\hline \multirow{5}{*}{$\begin{array}{l}\text { Modelling action } \\
\text { into a new concept }\end{array}$} & 8 & $\begin{array}{l}\text { Concluding a new structure with }\left(2 . A_{k}\right)^{m} \text { as the strategy for the next } \\
\text { stage. }\end{array}$ \\
\hline & 9 & Defining variable $m$ as $m=\left\{\begin{array}{lll}m=0 & \text { jika } & l=1 \\
m=1 & \text { jika } & l=2 \\
m=2 & \text { jika } & l=0\end{array}\right.$ \\
\hline & 10 & Defining $A_{k}$ as natural number to- $k$. \\
\hline & 11 & $\begin{array}{l}\text { Stating relationship between } k \text { in } n \text {, which } k \text { was the quotient of } \\
\frac{n+2}{3}\end{array}$ \\
\hline & 12 & $\begin{array}{l}\text { Stating relationship between } l \text { om } n \text {, which } l \text { was the residual } \\
\text { division of } \frac{n}{3}\end{array}$ \\
\hline $\begin{array}{l}\text { Concluding the } \\
\text { concept or new } \\
\text { knowledge as } \\
\text { general formula of } \\
\text { the } n \text {-th term }\end{array}$ & 13 & $\begin{array}{l}\text { Drawing a conclusion by stating that } U_{n}=\left(2 . A_{k}\right)^{m} \text { is the general } \\
\text { formula of the } n \text {th term. }\end{array}$ \\
\hline
\end{tabular}

Table 2 explains the connectivity between solution stages of subject S5's reflective abstraction with the level of reflective abstraction, while Table 3 classifies the solution indicators based on the solution stages.

The results of this study should be followed up with further discussion about the relation among stages, processes, and levels of reflective abstraction. Combining Piaget's, Dubinsky's and Cifarelli's theories of reflective abstraction should be treated as a crucial challenge in mathematics education as a field. Finding the formal form in constructing arithmetic or geometric sequence from random sequence number could be a noteworthy material in high school mathematics education study. One way to realize it could be in the form of developing model of applicable school mathematics material which can cultivate students' abstraction skills or students' reflective abstraction competence in solving mathematical problems.

\section{Conclusions}

Students' reflective abstraction stage in solving sequence number problem usually begins with the phase of in-depth observing pre-determined pattern of the sequence numbers. It is then followed by action planning stage towards the pre-existed pattern to authenticate a new pattern. In the next stage, the students design strategies or create a new pattern by constructing characteristics of the known pattern.

Furthermore, the next stage starts with compiling, re-organizing, formulating activities, modelling stage, and anticipating new appearing concepts. Then, the concluding reflective abstraction results in the form of general formulation by defining the results. The last phase ends by investigating the validity of findings and formulation, and by testing its general truth.

The reflective abstraction stages related to its level consists of recognition, representation, structural abstraction, and structural awareness. 
The stages do not indicate its reflective abstraction level, meaning that the stages are neither directly proportioned to, nor inversely proportioned to level of reflective abstraction. On the contrary, the level of reflective abstraction provides supports towards its determined stage, meaning that the particular stage with certain level gives meaning to the stage.

\section{Disclosure statement}

No potential conflict of interest was reported by the authors.

\section{Notes on contributors}

Mohammad Djasuli, Sekolah Menengah Atas (SMA) Negeri 4 Pasuruan, Indonesia.

Cholis Sa'dijah, Universitas Negeri Malang, Indonesia.

I Nengah Parta, Universitas Negeri Malang, Indonesia.

Tjang Daniel Chandra, Universitas Negeri Malang, Indonesia.

\section{References}

Abrahamson, D. (2006). Exposing Piaget's Scheme: Empirical Evidence for the Ontogenesis of Coordination in Learning a Mathematical Concept. University of California, Berkeley.

Belbase, S. (2010). A Reflective Journey through Theory and Research in Mathematical Learning and Development. Retrieved from http://files.eric.ed.gov/fulltext/ED514497.pdf

Beth, E. W., \& Piaget, J. (1966). Mathematical Epistemology and Psychology. Dordrecht, The Netherlands: D. Reidel.

Bowie, L. 1998. A Learning Theory Approach to Students' Misconceptions in Calculus. Thesis. University of Cape Town, South Africa. Retrieved from https://open.uct.ac.za/bitstream/ handle/11427/9556/thesis_sci_1998_bowie_l.pdf?sequence=1

Carter, P. \& Russel, K. (2004). The Complete Book of Fun Maths, 250 Confidence Boosting Tricks, Test and Puzzles. New York, NY: John Wiley \& Sons. Retrieved from http://as.wiley.com/WileyCDA/WileyTitle/productCd-0470870915.html

Clark, D.A. (2014). The Wiley Handbook of Cognitive Behavioral Therapy. First Edition. New York, NY: Guilford Press.

Copley, J. (2013). Mathematical Thinking. Retrieved from http://images.pearsonclinical.com/images/ Assets/WSS 5/Research Summary_Mathematical Thinking_FNL.pdf

Creswell, J.W. (2014). Research Design: Qualitative, Quantitative, and Mixed Methods Approaches. Fourth Edition. Sage Publications.

Chrisopher, J.C. \& Campbell, R.L. (2008). An Interactivist-Hermeneutic Metatheory for Positive Psychology. Theory \& Psychology. Vol. 18(5), 675-697. Sage Publications. DOI: 10.1177/ 0959354308093401 Retrieved from http://tap.sagepub.com.

Dubinsky, Ed. (1992). Reflective Abstraction in Advanced Mathematical. In Advanced Mathematical Thinking. David Tall (ed), 95-123. Dordrecht, The Netherlands: Kluwer Academic Publisher.

Ferrari, P.L. (2003). Abstraction in Mathematics. Philosophical Transactions of the Royal Society B: Biological Sciences. Vol. 358(1435): 1225-1230. doi: 10.1098/rstb.2003.1316

Glasersfeld, Ernst von. (1991). Abstraction, Re-Presentation, and Reflection. In Epistemological foundations of mathematical experience. L.P. Steffe (Ed). New York, NY: Springer.

Goedecke, J. (2013). Abstraction in Mathematics. A course material on powerpoint file. Queen's College. Retrieved from https://www.dpmms.cam.ac.uk/ jg352/pdf/TMSTalk.pdf

Gray, E. \& Tall, D. (2001). Relationships between Embodied Objects and Symbolic Procepts: An Explanatory Theory of Success and Failure in Mathematics. Retrieved from http://homepages.warwick.ac.uk/staff/David.Tall/pdfs/dot-pme25-pinto-tall.pdf

Hazzan, O \& Zazkis, R. (2005). Reducing Abstraction: The Case of School Mathematics. Retrieved from http://www.sfu.ca/ zazkis/publications/Reducing\%20Abstraction.pdf

Kasali, R. (2006). Change! Cetakan ke delapan. Jakarta: PT Gramedia Pustaka Utama. 
Kumar, R. (2011). Research Methodology: a step-by-step guide for beginners. Third Edition. Sage Publications, Inc.

Marlow, E. (1990). Psychological Foundations in Teaching Mathematics. Retrieved from http://files.eric.ed.gov/fulltext/ED431606.pdf

Mason, J., Burton, L. \& Stacey, K. (2010), Thinking Mathematically. Second Edition. England: Pearson Education Limited.

Michelmore, M \& White, P. (2004). Abstraction in Mathematics and Mathematics Learning. In Proceedings of the 28th Conference of the International Group for the Psychology of Mathematics Education. Vol 3, 329-336. Retrieved from https://www.emis.de/ proceedings/PME28/RR/RR031_Mitchelmore.pdf

Mitchelmore, M. \& White, P. (2007). Abstraction in Mathematics Learning. In Mathematics Education Research Journal. Vol 19(2), 1-9.

Mousoulides, N. \& Gagatsis, A. (2004). Algebraic and Geometry. Approach in Function Problem Solving. Retrieved from http:// files.eric.ed.gov/fulltext/ED489596.pdf

Ozmantar, F. M. \& Monaghan, J. (2007). A Dialectical Approach to Formation of Mathematical Abstractions. Mathematics Education Research Journal,Vol.19 (2), 89-112.

Panasuk, R. M. (2011). Taxonomy for Assessing Conceptual Understanding in Algebra Using Multiple Representation. College Student Journal, Vol. 45 (2), 219-232. Spring Hill Station, Mobile, AL. Retrieved from http://jasonadair.wiki.westga.edu/file/view/Taxonomy+for+ assessing+conceptual+understanding+in+Algebra+using+multiple+representations.pdf

Paschos, T. \& Farmaki, V. (2006). The Reflective Abstraction in the Construction of the Concept of the Definite Integral: A Case Study. Retrieved from ftp://ftp.math.ethz.ch/EMIS/proceedings/ PME30/4/337.pdf),

Ruch, F.L. (1967). Psychology and Life. Glenview, IL: Scott Foresman.

Schoenfeld, A.H. (1992). Learning to Think Mathematically: Problem Solving, Metacognition, and Sense Making in Mathematics. In: D. Grouws (Ed). Handbook for Research on Mathematics Teaching and Learning. New York, NY: MacMillan.

Silver, H.F., Brunsting, J.R., Walsh, T. \& Thomas, E.J. (2012). Math Tools, Grades 3-12. 60+ Ways to Build Mathematical Practices, Differentiate Instruction, and Increase Student Engagement. Second Edition. Sage Publishing.

Solso, R.L, MacLin, O.H. \& MacLin, M.K. (2008) Cognitive Psychology. Eighth Edition. Pearson.

Stacey, K. (2014) What is mathematical thinking and why is it important? Retrieved from https://www.researchgate.net/publication/254408829

Tall, D. (2002) Advanced Mathematical Thinking. New York, NY: Kluwer Academic Publishers.

Tall, D. (2009) The Development of Mathematical Thinking: Problem-Solving and Proof. Retrieved from http://homepages.warwick.ac.uk/staff/David.Tall/pdfs/dot2009d-paper-for-john mason.pdf

Turnau, S. (Ed) (2008). Handbook of Mathematics Teaching Improvement:Professional Practices that Address PISA. Output of the Krygowska Project. "Professional Development of TeacherResearchers" 2005-2008. University of Rzeszów. KSERKOP, Kraków, Poland: Drukarnia Cyfrowa.

Walle, J. A.V. (2007). Elementary and Middle School Mathematics. Cetakan ke-tujuh. Jakarta: Penerbit Erlangga.

Zimbardo, P.G. \& Ruch, F.L. (1977). Psychology and Life. Ninth Edition. Chicago, Illinois: Pearson Scott Foresman.

Zull, J. E. (2002). The Art of Changing the Brain. Sterling, VA: Stylush Publishing. 